\title{
Prevalence of Substance Abuse/Alcohol Consumption and their Predictors among Patients Admitted in Operating Rooms of a General Educational Hospital, Tehran, Iran
}

\author{
S. Shohreh Alavi ${ }^{1}$, Ramin Mehrdad ${ }^{1}$ and Jalil Makarem ${ }^{2^{*}}$ \\ 'Center for Research on Occupational Diseases, Tehran University of Medical Sciences, Tehran, Iran \\ ${ }^{2}$ Imam Khomeini Hospital Complex, Tehran University of Medical Sciences, Tehran, Iran; j-makarem@tums.ac.ir
}

\begin{abstract}
Substance/alcohol abuse is an important public health threat in most countries. Social stigmatization and legal restrictions prevent accurate and direct estimate of prevalence of substance/alcohol abuse in Iran. This study aimed to estimate of the prevalence of alcohol and substance use among Iranian patients who were admitted to operating rooms of a general hospital in Tehran and identified risk factors that may predict alcohol and substance use. This cross-sectional study was conducted among all consecutive patients who were admitted to 16 operating rooms in Vali-e-Asr General Educational Hospital (Tehran, Iran) during March 2014 to September 2015. Data were derived from a medical history form prior to operation by trained nurses who were working in the operating rooms. Among 1136 patients admitted to operating rooms, $105(28.7 \%)$ men and 21 (2.7\%) women were substance/alcohol users. The main substance of abuse was opium (57.3\%) followed by alcohol consumption (25.6\%) and water pipe smoking (14.8\%). Cigarette smoking was reported by $110(30.1 \%)$ men and $21(2.7 \%)$ women. Sex, cigarette smoking and family history of alcohol and substance abuse predicted $42.3 \%$ of the variance in substance abuse/alcohol consumption. Substance use, especially opium, alcohol, water pipe tobacco and cigarette smoking were found to be significantly high particularly among male patients. Being a man, current cigarette smoking and having a first-degree family member who had abused substances should be considered when planning preventive or therapeutic programs.
\end{abstract}

Keywords: Alcohol Drinking, Prevalence, Smoking, Substance Abuse

\section{Introduction}

Nowadays, most societies face the serious challenge of substance abuse, which is often associated with social problems. Substance abuse is closely related to cultural, religious, economic, social, and historical aspects of a Community ${ }^{1}$. Official statistics and indirect estimations declared the approximate total number of addicts in Iran to be between 700,000 and 4,000,000. However, these estimations are in-accurate and crude $^{2}$. In other words, accurate assessment of the prevalence of substance and alcohol abuse and dependence (due to legal and religious restrictions and social stigmatization) is not possible in
Iran, because respondents may not always be honest or accurate about their substance use. On the other hand, substance and alcohol abuse have acute and chronic physical harms to the organs of users ${ }^{3}$ and complicate the health problems of the medical patients ${ }^{1,4,5}$ so using these substances increase the rate of physical co-morbidities ${ }^{6}$. Some of the consequences of opium/opioid use are listed as follows:

- Changes in biochemical parameters of human's serum ${ }^{7}$;

- Difficulties in Peri-operative pain management;

- A high tolerance for opiate analgesics and a need to higher and more frequent doses to achieve desired 
effects and higher probability to be under medicated for pain ${ }^{8}$;

- Shorter duration of spinal anesthesia';

- Difficulties in intravenous access in injection drug users due to phlebitis.

- A higher risk of thrombophlebitis, infection at the injecting site, bacteremia, sepsis, Human Immunodeficiency Virus (HIV) and Hepatitis C Virus $(\mathrm{HCV})^{8,10}$.

- The risk of violent behavior and psychological problems, withdrawal syndrome, and lack of postoperative cooperation ${ }^{5}$.

Smoking and hazardous drinking can also affect human physiology in different ways. The systems most commonly affected by smoking are pulmonary, cardiovascular and the immune system ${ }^{11}$. Tissue healing and hepatic metabolization of many drugs are other complications that may be caused by smoking and drinking ${ }^{12}$. In addition to system affected by alcohol such as liver, pancreas, and nervous system, heavy drinking may complicate cardiac function, immune capacity, haemostasis, metabolic stress response and muscular dysfunction ${ }^{13}$. Furthermore, postoperative infections and bleeding episodes are among the most occurring alcohol complications ${ }^{14}$. Given the aforementioned complications, the patients admitted to operating rooms need supportive cares such as an increased dose of drugs during the operation and recovery in order to deal with the adverse effects of substance and alcohol abuse. Unfortunately, if not considered as the primary disorders, substance and alcohol abuse will be neglected and barely diagnosed ${ }^{15,16}$. While this is the case, general hospitals are appropriate places for diagnosis and treatment of substances/alcohol abuse as well as necessary interventions to manage related complications ${ }^{17}$. A study of the patients suffering from chronic kidney failure who were admitted in Shiraz (a city in Iran) General Hospitals demonstrated a 14.1\% opium abuse followed by tobacco (25.9\%) and alcohol $(3.1 \%)^{18}$. Another study of patients with heart diseases reported a $36.5 \%$ tobacco, $9 \%$ opium and $8 \%$ alcohol abuse ${ }^{19}$. In addition, in a cross-sectional study in Urmia University of Medical Sciences, 2.5\% Iranian orthopedic inpatients were opium/opioid users ${ }^{20}$. Another study among 64 Iranian nephrologic patients who were admitted at Shiraz general hospitals reported that $31.3 \%$ of the subjects were substance, $28.1 \%$ nicotine and, 9.4\% opium dependent ${ }^{18}$. It is not sufficient up to date research on the prevalence of substance abuse and alcohol drinking in Iranian general hospitals and few research were done, only focused on patients with a particular disease or patients hospitalized in a special ward of a hospital. Therefore, the objective of this study is to estimate the prevalence of alcohol and drug use in patients admitted to the operating rooms of a general hospital at Tehran University of Medical Sciences (TUMS), Tehran, the capital of Iran. In addition, present research investigated predictors of smoking, alcohol use, and substance abuse among factors significant in the univariate analysis.

\section{Materials and Methods}

This cross-sectional study included all consecutive patients admitted to 16 operating rooms in Vali-eAsr General Hospital affiliated to TUMS. A sampling of patients was according to census method. All new consecutive patients admitted to the operating rooms were asked to respond the questions during waiting time prior to operation by a team of trained nurses working in the operating rooms. Patients less than 10 years of age and those with a medical condition, which prevented them from responding to the questionnaire (such as unconscious patients), were excluded from the study. The data were collected by means of a medical history form every morning, seven-day-a-week during March 2014 to September 2015. The medical history form included demographic characteristics such as sex, age, educational level, marital status and occupational status, as well as questions regarding the history of associated diseases, history of psychiatric disorders, history of medical drugs, cigarette smoking, alcohol consumption, substance abuse, frequency and pattern of alcohol, cigarette and substance usage and methods of substance abuse (swallowing, smoking, snorting and injecting). In the present study, substance abuse was considered as the consumption of the substances without a medical prescription. The substances included opium, shireh, heroin, morphine, methadone, hashish and amphetamine derivatives. Alcohol consumption was defined as having drunk alcohol during the last 3 months. Because of the social stigma and legal restrictions on substance abuse/alcohol consumption in Iran, some patients might not initially be honest or accurate about their abuse habits. On the other hand, in order to predict adverse drug interactions, predict tolerance to some anesthetic agents and recognize 
drug-withdrawal signs and symptoms, it is necessary to be aware of the patient's history of substance abuse prior to administering anesthesia or analgesia. In addition, identifying alcohol use disorders is necessary because of physical co-morbidities. Therefore, the purpose of the questions has been carefully explained to the patients and they were assured that their responses were regarded confidential and would be used only in clinical decisions. In addition, details of the study were explained to the patients orally before completing the medical history forms and the written informed consent was obtained. The Medical Ethics Committee of TUMS has approved the study protocol. Descriptive statistics were used to find out the participants' characteristics in a two-sex group (male and female). To compare categorical variables between the sex groups and respondents with or without substance abuse/alcohol consumption, Chi-square test was conducted. Continuous variables were tested by independent samples T-test. Multivariate analyses using binary logistic regression were performed to find out predictors of substance abuse/alcohol consumption. A P-value of $<0.05$ was considered statistically significant.

\section{Results}

Of 1136 patients admitted to operating rooms, 366 (32.2\%) were male and $770(67.8 \%)$ were female. The mean $( \pm$ SD) ages of male and female patients were $39.2 \pm$ 16.7 and $38.4 \pm 13.3$, respectively. Substance abuse/alcohol consumption was reported by $105(28.7 \%)$ male patients and $21(2.7 \%)$ female ones $(\mathrm{P}<0.001)$. One hundred and ten men $(30.1 \%)$ and $21(2.7 \%)$ women had the habit of cigarette smoking which was statistically significant $(\mathrm{P}<0.001)$. The results showed that $48(13.1 \%)$ male patients and 70 (9.1\%) female ones had a family history of substance abuse/alcohol consumption $(\mathrm{P}=0.03)$. Selected characteristics of the patients and significant differences between the sex subgroups are provided in Table 1.

Among the occupational groups, housewives (52.3\%), employees (17.3\%) and workers $(17.0 \%)$ were more reported. In addition, workers (38.9\%), employees (25.4\%) and housewives (11.9\%) were occupations with higher rates among abusers (Table 2).
Table 1. Selected participants' characteristics as regards sex

\begin{tabular}{|c|c|c|c|c|}
\hline Variable & $\begin{array}{c}\text { Total } \\
(\mathrm{n}=1136) \\
\mathrm{N}(\%) \\
\end{array}$ & $\begin{array}{c}\text { Male } \\
(\mathrm{n}=366) \\
\mathrm{N}(\%)\end{array}$ & $\begin{array}{c}\text { Female } \\
(\mathrm{n}=770) \\
\mathrm{N}(\%)\end{array}$ & P-value \\
\hline \multicolumn{5}{|c|}{ Level of education } \\
\hline $\begin{array}{l}\text { Lower than } \\
\text { diploma }\end{array}$ & $516(45.4)$ & $172(47.0)$ & $344(44.7)$ & \multirow[t]{6}{*}{0.78} \\
\hline $\begin{array}{l}\text { High school } \\
\text { diploma }\end{array}$ & $411(36.2)$ & $124(33.9)$ & $287(37.3)$ & \\
\hline Associate & $51(4.5)$ & $14(3.8)$ & $37(4.8)$ & \\
\hline Bachelor & $131(11.5)$ & $46(12.6)$ & $85(11.0)$ & \\
\hline Master & $18(1.6)$ & $7(1.9)$ & $11(1.4)$ & \\
\hline $\mathrm{PhD}$ & $9(0.8)$ & $3(0.8)$ & $6(0.8)$ & \\
\hline \multicolumn{5}{|c|}{ Marital status } \\
\hline Married & $880(77.5)$ & $233(63.7)$ & $647(84.0)$ & \multirow[t]{2}{*}{$<0.001$} \\
\hline Single & $256(22.5)$ & $133(36.3)$ & $123(16.0)$ & \\
\hline \multicolumn{5}{|c|}{ Occupational status } \\
\hline Employed & $456(40.1)$ & $288(78.7)$ & $168(21.8)$ & \multirow[t]{2}{*}{$<0.001$} \\
\hline Unemployed & $680(59.9)$ & $78(21.3)$ & $602(78.2)$ & \\
\hline \multicolumn{5}{|c|}{ History of medical drugs } \\
\hline Yes & $299(26.3)$ & $66(18.0)$ & $233(30.3)$ & \multirow[t]{2}{*}{$<0.001$} \\
\hline No & $837(73.7)$ & $300(82.0)$ & $537(69.7)$ & \\
\hline \multicolumn{5}{|c|}{ History of associated diseases } \\
\hline Yes & $337(29.7)$ & $83(22.7)$ & $254(33.0)$ & \multirow[t]{2}{*}{$<0.001$} \\
\hline No & $799(70.3)$ & $283(77.3)$ & $516(67.0)$ & \\
\hline \multicolumn{5}{|c|}{ History of psychiatric disorders } \\
\hline Yes & $47(4.1)$ & $11(3.0)$ & $36(4.7)$ & \multirow[t]{2}{*}{0.12} \\
\hline No & $\begin{array}{c}1089 \\
(95.9) \\
\end{array}$ & $355(97.0)$ & $734(95.3)$ & \\
\hline \multicolumn{5}{|c|}{ Smoking } \\
\hline Yes & $131(11.5)$ & $110(30.0)$ & $21(2.7)$ & \multirow[t]{2}{*}{$<0.001$} \\
\hline No & $\begin{array}{c}1005 \\
(88.5)\end{array}$ & $256(70.0)$ & $749(97.3)$ & \\
\hline \multicolumn{5}{|c|}{ Substance abuse/alcohol consumption } \\
\hline Yes & $126(11.1)$ & $105(28.7)$ & $21(2.7)$ & \multirow[t]{2}{*}{$<0.001$} \\
\hline No & $\begin{array}{c}1010 \\
(88.9) \\
\end{array}$ & $261(71.3)$ & $749(97.3)$ & \\
\hline \multicolumn{5}{|c|}{ Family history of substance abuse/alcohol consumption } \\
\hline Yes & $118(10.4)$ & $48(13.1)$ & $70(9.1)$ & \multirow[t]{2}{*}{0.03} \\
\hline No & $\begin{array}{c}1018 \\
(89.6)\end{array}$ & $318(86.9)$ & $700(90.9)$ & \\
\hline
\end{tabular}

The most frequent substances which were used consisted opium (57.3\%) followed by alcohol (25.6\%) and tobacco smoking using a water pipe (14.8\%). Swallowing 
Table 2. Participants' occupations as regards substance abuse/alcohol consumption

\begin{tabular}{lcccc}
\hline Occupations & Total (n=1136) N (\%) & $\begin{array}{c}\text { No substance abuse/alcohol } \\
\text { consumption }(\mathbf{n}=1010) \mathbf{N}(\%)\end{array}$ & $\begin{array}{c}\text { Substance abuse/alcohol } \\
\text { consumption (n=126) } \mathbf{N}(\%)\end{array}$ & P-value \\
\hline Housewife & $594(52.3)$ & $579(57.3)$ & $15(11.9)$ & \\
Employee & $196(17.3)$ & $164(16.2)$ & $32(25.4)$ & \\
Worker & $193(17.0)$ & $144(14.2)$ & $49(38.9)$ & \\
University Student & $44(3.8)$ & $39(3.9)$ & $5(4.0)$ & $<0.001$ \\
School Student & $40(3.5)$ & $39(3.9)$ & $1(0.8)$ & \\
Jobless & $33(2.9)$ & $20(2.0)$ & $13(10.3)$ & \\
Driver & $25(2.2)$ & $15(1.5)$ & $10(7.9)$ & \\
Doctor & $8(0.7)$ & $8(0.8)$ & $10(0.8)$ & \\
Soldier & $3(0.3)$ & $2(0.2)$ & & \\
\hline
\end{tabular}

(49.5\%) and smoking (55.0\%) was the most prevalent methods used by consumers (Table 3 ).

Table 3. Type and methods of substance abuse

\begin{tabular}{lc}
\hline Variable & Frequency $(\%)^{*}$ \\
\hline \multicolumn{1}{c}{ Type of abused substance } \\
\hline Opium and shireh & $54(57.3)$ \\
Alcohol & $24(25.6)$ \\
Water pipe & $14(14.8)$ \\
Cigarette & $131(11.5)$ \\
Amphetamine derivatives & $7(10.9)$ \\
Methadone & $4(4.3)$ \\
Other drugs & $10(11.0)$ \\
\hline
\end{tabular}

\begin{tabular}{lc}
\hline \multicolumn{2}{c}{ Methods of substance abuse } \\
\hline Swallowing & $47(49.5)$ \\
Smoking & $52(55.0)$ \\
Snorting & $3(3.3)$ \\
Injecting & $3(3.3)$ \\
\hline${ }^{*}$ Someparticipantsused morethanonetypeofsubstanceormethod. \\
${ }_{* \star}$ Other drugs consisted of hashish, tramadol, heroin, morphine.
\end{tabular}

Based on the results, there were a significant relationship between family history of substance abuse/ alcohol consumption $(\mathrm{P}<0.001)$, smoking $(\mathrm{P}<0.001)$, occupational status $(\mathrm{P}<0.001)$, marital status $(\mathrm{P}=0.001)$, sex $(<0.001)$ and substance abuse/alcohol consumption (Table 4).

According to the results of the binary logistic regression analysis shown in Table 5, sex, smoking and family history of alcohol and substance abuse were significant predictors of substance abuse/alcohol consumption. Male patients $(\mathrm{OR}=8.448,95 \% \mathrm{CI}: 4.895-14.580)$, current smokers (OR=7.134, 95\% CI: 4.365-11.662) and patients with a history of substance abuse/alcohol consumption in their family (OR=5.595, 95\% CI: 3.138-9.975) were significantly more likely to abuse substances and consume alcohol. In other words, these three variables accounted for $42.3 \%$ of the total variance in predicting substance abuse/alcohol consumption.

\section{Discussion}

Social stigmatism and legal restrictions on substance abuse/alcohol consumption in Iran prevent abusers and alcohol consumers from admitting their habits and this situation make it impossible to estimate the prevalence of drug abuse/alcohol consumption directly. Hospitals and medical centers to which patients are referred are one of the reliable sources of information regarding the status of substance abuse/alcohol consumption ${ }^{2}$. According to this study, approximately one-third of male patients who were admitted to operating rooms reported substance abuse or alcohol consumption, but the prevalence of drinking alcohol or substance abuse among females were only $2.7 \%$. It was similar to $30.1 \%$ and $2.7 \%$ prevalence of cigarette smoking among men and women, respectively. However, the number of women in this study was more than twice that of men. In line with this study, several surveys in Iran and the world documented this pattern of gender differences among different study populations over the years ${ }^{2,6,18,20}$. This represents a significant prevalence of substance abuse, alcohol consumption, and cigarette smoking among the studied men. Although gender differences were not our primary purpose and this study does not describe their potential reasons, it reveals the fact that these differences exist. This may help to design preventive and curative interventions with a focus on high-risk sex. In addition, a significant relationship between sex and substance abuse/alcohol consumption indicated that the rates between men and women should be reported separately because pooling the rate of substance abuse/alcohol consumption of the men and 
Table 4. Selected participants' characteristics as regards substance abuse/alcohol consumption

\begin{tabular}{|c|c|c|c|}
\hline Variable & $\begin{array}{l}\text { No substance abuse/alcohol } \\
\text { consumption }(\mathrm{n}=1010) \mathrm{N}(\%)\end{array}$ & $\begin{array}{c}\text { Substance abuse/alcohol con- } \\
\text { sumption }(\mathrm{n}=126) \mathrm{N}(\%)\end{array}$ & P-value \\
\hline \multicolumn{4}{|c|}{ Level of education } \\
\hline Lower than diploma & $457(45.2)$ & $59(46.8)$ & \multirow[t]{6}{*}{0.62} \\
\hline High school diploma & $371(36.7)$ & $40(31.7)$ & \\
\hline Associate & $44(4.4)$ & $7(5.6)$ & \\
\hline Bachelor & $116(11.5)$ & $15(11.9)$ & \\
\hline Master & $14(1.4)$ & $4(3.2)$ & \\
\hline $\mathrm{PhD}$ & $8(0.8)$ & $1(0.8)$ & \\
\hline \multicolumn{4}{|c|}{ Marital status } \\
\hline Married & $797(78.9)$ & $83(65.9)$ & \multirow[t]{2}{*}{0.001} \\
\hline Single & $213(21.1)$ & $43(34.1)$ & \\
\hline \multicolumn{4}{|l|}{ Occupational status } \\
\hline Employed & $368(36.4)$ & $88(69.8)$ & \multirow[t]{2}{*}{$<0.001$} \\
\hline Unemployed & $642(63.6)$ & $38(30.2)$ & \\
\hline \multicolumn{4}{|c|}{ History of medical drugs } \\
\hline Yes & $270(26.7)$ & $29(23.0)$ & \multirow[t]{2}{*}{0.21} \\
\hline No & $740(73.3)$ & $97(77.0)$ & \\
\hline \multicolumn{4}{|c|}{ History of associated diseases } \\
\hline Yes & $311(29.9)$ & $26(27.4)$ & \multirow[t]{2}{*}{0.35} \\
\hline No & $730(70.1)$ & $69(72.6)$ & \\
\hline \multicolumn{4}{|c|}{ History of psychiatric disorders } \\
\hline Yes & $40(4.0)$ & $7(5.6)$ & \multirow[t]{2}{*}{0.30} \\
\hline No & $970(96.0)$ & $119(94.4)$ & \\
\hline \multicolumn{4}{|l|}{ Smoking } \\
\hline Yes & $62(6.1)$ & $69(54.8)$ & \multirow[t]{2}{*}{$<0.001$} \\
\hline No & $948(93.9)$ & $57(45.2)$ & \\
\hline \multicolumn{4}{|c|}{ Family history of alcohol and substance abuse } \\
\hline Yes & $78(7.7)$ & $40(31.7)$ & \multirow[t]{2}{*}{$<0.001$} \\
\hline No & $932(92.3)$ & $86(68.3)$ & \\
\hline
\end{tabular}

Table 5. Binary logistic regression analysis of independent risk factors potentially predict substance abuse/alcohol consumption

\begin{tabular}{lcccccc}
\hline Variable & B & SE & OR & P & \multicolumn{2}{c}{ 95\% CI for OR } \\
\cline { 4 - 7 } & & & & & Lower & Upper \\
\hline Sex (male) & 2.134 & 0.278 & 8.448 & $<0.001$ & 4.895 & 14.580 \\
Current cigarette smoking (yes) & 1.965 & 0.251 & 7.134 & $<0.001$ & 4.365 & 11.662 \\
Family history of alcohol and substance abuse (yes) & 1.722 & 0.295 & 5.595 & $<0.001$ & 3.138 & 9.975 \\
Constant & -4.054 & 0.249 & & & & \\
Nagelkerke R-square & & \multicolumn{2}{c}{0.423} & & & \\
\hline
\end{tabular}

Note: Non-significant variables in univariate analyses were not shown in multivariate model.

women together leads to a dilution effect and lowers the total prevalence estimations. Similar to other Iranian surveys, this research revealed that opium was the most commonly used substances ${ }^{2,4,21}$. It was interesting that while producing and consuming alcohol is illegal in Iran and consumers try to hide it even from their relatives, alcohol consumption was the second most commonly used substances. Another study by Ardebili ${ }^{22}$ in a household study in Tehran showed alcohol and opioids were the most frequently used substances, respectively. They cautioned about a hidden epidemic of alcohol abuse and dependency in Iran. This issue needs serious attention 
because alcohol prohibition policy increases the possibility of drinking house-made and fake alcohols and causes serious adverse effects on health. On the other hand, abuse of alcohol is not considered as a serious health problem because of alcohol prohibition, so sufficient resources for its prevention and treatment are not allocated. Among the most common addictive substances, third place belonged to water pipe tobacco smoking. Many water pipe tobacco smokers believe that this form of tobacco use is benign. Unfortunately, due to this common misconception about water pipe that it is not addictive, or at least not as addictive as cigarettes, its use has become a growing health concern globally and especially among young adults. On the other hand, prevention/treatment interventions often pay little attention to water pipe tobacco smoking ${ }^{22}$. By including water pipe smoking in tobacco prevention and control programs, involving people, including physicians, policy makers, and tobacco control advocates can play an important role in eliminating these misconceptions among water pipe users and can be effective in limiting its spread. There was no significant relationship between substance abuse/alcohol consumption and patients' level of education, history of psychiatric disorders, history of associated diseases and history of medical drugs. The relationship between substance abuse and participants' level of education has been the subject of much controversy in published literature. For example, a study on the frequency of alcohol and substance abuse among drivers who had been killed in traffic accidents in Hamadan (a city in Iran) revealed that drivers with higher levels of education (high school diploma or higher) were more likely to abuse substance or drink alcohol ${ }^{23}$. On the contrary, there was no relationship between education and substance abuse among nephrologic patients admitted in Shiraz general hospitals ${ }^{24}$. Contradictory findings concerning the relationship between substance use and a history of psychiatric disorders have been reported. Substance use may be followed by psychiatric disorders or developed as a result of it, it may occur independently of these disorders or they may affect its severity. Substance use and psychiatric disorders may originate from a common vulnerability ${ }^{25}$. In a review on the relationship between substance abuse and physical diseases, researchers found preliminary evidence suggesting these substances may predispose abusers to several physical health disorders ${ }^{26}$. Other researchers believe that only moderate to heavy use of drugs and alcohol consumption increase specific health risks and physical disorders among women ${ }^{27}$. In line with the present study, $\mathrm{McCabe}^{28}$ showed that medical drug users without a history of nonmedical use were generally not at increased risk of drug abuse. The final regression model indicated that men had a 2.1-fold higher risk of substance abuse/alcohol consumption compared with women. Interestingly, only about one-third of admitted patients to operating rooms were men. However, male sex was a significant predictor of substance abuse/alcohol consumption. This situation was the same in most research conducted on the subject of addiction in Iran and the world ${ }^{18,20,29,30}$. Cultural constructs, including gender socialization (i.e., the learning of and conformity to appropriate masculine and feminine traits) and stratification (e.g., unequal economic, educational, and social opportunities) can explain genderspecific etiological differences in substance and alcohol consumption $^{31}$. The most common theoretical issues regarding gender differences on alcohol drinking were mentioned by the World Health Organization (WHO) as power, sex, risks, and responsibilities. According to the WHO, alcohol may help aggressive men to increase their power over other people to bully them. It may improve sexual performance and enjoyment in both sexes. Alcohol drinking chemically motivates men to take risks and demonstrate masculinity (but not femininity). The final hypotheses to explain why men and women differ in their drinking behavior states that heavy drinking helps men to ignore their responsibilities. However, in women cases, high responsibility, particularly at home, may restrict their drinking ${ }^{32}$. Gender must be viewed as more than a control variable or a sampling consideration. Policy makers must consider it when defining laws, programs, and policies so will be better equipped to meet the drugrelated challenges of the twenty-first century. In addition, current smoking was linked with 1.9 times increased risk of substance abuse/alcohol consumption. These findings support those of the study of Degenhardt and Hall ${ }^{33}$, in which current use of tobacco was strongly correlated with substance/alcohol abuse/dependence. The issue of why the use of substances is correlated with smoking has been the subject of considerable debate. One view, the "gateway hypothesis", proposes that substance use progresses through stages, the earliest substances may be tobacco and alcohol, which may progress to the use of so-called "hard" drugs such as cannabis. Another hypothesis states that genetic factors may play a role in increasing the likelihood of alcohol dependence ${ }^{34}$, cannabis 
dependence $^{35}$, nicotine dependence ${ }^{36}$ and cocaine dependence ${ }^{37}$. Given that different substance act upon the same neurotransmitters, it is possible that vulnerabilities may be similar across different substance types. It suggests that the same vulnerabilities that predispose an individual to smoke may also predispose him/her to alcoholism. Since cigarette smoking can be considered as a predisposing factor of substance/alcohol abuse, smoking treatment could be useful as a method of preventing substance/alcohol abuse. Unfortunately, in our country, Iran, cigarette smoking and water pipe tobacco smoking as serious risk factors for experiencing alcohol and other substances does not receive the necessary attention and there is a strong need to inform people in different ways to convey the message that water pipe and cigarette smoking are addictive and can provide an opening to the more addictive and dangerous substances. Patients with a family history of substance abuse/ alcohol consumption were 1.7 times more likely to abuse substance/consume alcohol than their counterparts without a family history (based on the multivariate model of logistic regression, Table 5). Consistent with our study, a review article on the status of substance abuse in 2002 documented that approximately half of Iranian substance abusers had at least a first-degree family member who had abused substances ${ }^{2}$. The results of numerous family studies have repeatedly indicated that relatives of substance users are at greater risk of using substances than both the general population and family members of non-substance users ${ }^{38,39}$. This relationship can be explained in different ways. First: individuals from families with a history of substance abuse tend to follow attitudes and behaviors of these relatives and more easily obtain the substances ${ }^{39}$. Second: family, twin, and adoption studies have strongly documented that genetic factors, at least in part, influence dependence on alcohol and other substances and their effects on families may continue for generations. This may justify elevated rates of substance addiction among the relatives of substance users ${ }^{40}$. Third: families may enhance the risk of substance use and abuse in their offspring through nonspecific mechanisms, which include disrupted family structure, marital discord, impaired parenting, exposure to stress, family psychopathology, neglect and abuse ${ }^{41}$. Familial context is a necessary component of successful management/treatment of substance/alcohol abuse. Therefore, substance treatment programs should screen other family members of abusers for substance use and involve those who screen positive to the $\operatorname{program}^{42}$. Furthermore, programs of proven effectiveness, which support families, need to be strengthened and developed so that families have the capacity to intervene at an early stage to prevent or delay early substance use. The present study has some strengths and limitations. Integrating all substances and alcohol use into one category and trusting in self-reports of the patients on their substance/alcohol use as well as that of family members were the weaknesses of the study. The strong point of this research was patients' voluntary cooperation. Patients knew that they would not be legally prosecuted in hospitals so they did not hide their habits. Another strong point was that there was no selection in the patient's admission in the setting of the study; the operating rooms of the general hospital.

\section{Conclusion}

According to the current study, it is concluded that, (i) the prevalence of substance abuse/alcohol consumption and cigarette smoking men, were significantly higher than women (the number of women was more than double that of men; whereas in men, the prevalence of drug use and smoking were ten times more than women). Therefore, it is necessary to evaluate substance abuse/ alcohol consumption in terms of gender, (ii) the most frequently used substances included opium, alcohol and tobacco smoking using a water pipe and (iii) being a man, current cigarette smoking and having a first degree family member who abused substances were identified as significant independent predictors of substance abuse/ alcohol drinking. Further studies focused on detection and management of risk factors which facilitate appropriate substance/alcohol prevention or treatment planning. In this regard, longitudinal studies of risk factors for substance/alcohol use are strongly recommended.

\section{Conflict of Interest}

None declared.

\section{Acknowledgements}

This study has been sponsored by the Vice Chancellor for Research in TUMS through contract no 93-02-109- 
25029. The authors sincerely appreciate the cooperation of the nurses of the operating rooms. They also acknowledge the valuable suggestions, comments, and English editing by Shervin Javanbakht.

\section{References}

1. Goreishizade M, Torabi K. A study of comorbidity of substance abuse and psychiatric disorders in self-referred addicts to Tabriz welfare centre. Medical Journal of Tabriz University of Medical Sciences. 2002; 55:49-53.

2. Mokri A. Brief overview of the status of drug abuse in Iran. Arch Iranian Med. 2002; 5(1):184-90.

3. Fox TP, Oliver G, Ellis SM. The destructive capacity of drug abuse: an overview exploring the harmful potential of drug abuse both to the individual and to society. ISRN Addiction. 2013; 2013(450348):6.

4. Ahmadi J, Pridmore S, Alimi A, Cheraghi A, Arad A, Parsaeyan H, Mohagheghzadeh MS, Kianpour M. Epidemiology of opium use in the general population. The American Journal of Drug and Alcohol Abuse. 2007; 33(1):483-91.

5. Rahimi MA, Sharifi V, Mohammadi MR, Farhodian A, Sahimi E, Rad R, et al. Researches on substance use in Iran 3 decades evaluation. Hakim Res J. 2006; 8(4):37-44.

6. Okay T, Şengul C, Acıkgöz Ç, Ozan G, Dilbaz N. Prevalence of alcohol dependence and abuse in a general hospital; sensitivity and specificity of MAST. European Journal of General Medicine. 2010; 7(1):10-5.

7. Kouros D, Tahereh H, Mohammadreza A, Minoo MZ. Opium and heroin alter biochemical parameters of human's serum. The American Journal of Drug and Alcohol Abuse. 2010; 36:135-9.

8. Kak V, Chandrasekar PH. Bone and joint infections in injection drug users. Infectious Disease Clinics of North America. 2002; 16(1):681-95.

9. Dabbagh A, Dahi-Taleghani M, Elyasi H, Vosoughian M, Malek B, Rajaei S, Maftuh H. Duration of spinal anesthesia with bupivacaine in chronic opium abusers undergoing lower extremity orthopedic surgery. Arch Iran Med. 2007; 10(1):316-20.

10. Schoener EP, Hopper JA, Pierre JD. Injection drug use in North America. Infectious Disease Clinics of North America. 2002; 16(1):535-51.

11. Warner M, Divertie M, Tinker J. Preoperative cessation of smoking and pulmonary complications in coronary artery bypass patients. Anesthesiology. 1984; 60(1):380-3.

12. Zevin S, Benowitz NL. Drug interactions with tobacco smoking. Clinical Pharmacokinetics. 199; 36(1):425-38.

13. Spies C, Tønnesen H, Andreasson S, Helander A, Conigrave K. Perioperative morbidity and mortality in chronic alcoholic patients. Alcoholism: Clinical and Experimental Research. 2001; 25(1):164S-70.

14. Tønnesen H. Alcohol abuse and postoperative morbidity. Dan Med Bull. 2003; 50:139-60.

15. Sri E, Raguram R, Srivastava M. Alcohol problems in a general hospital-a prevalence study. Journal of the Indian Medical Association. 1997; 95(1):505-6.

16. Bostwick JM, Seaman JS. Hospitalized patients and alcohol: who is being missed? General Hospital Psychiatry. 2004; 26(1):59-62.

17. Kouimtsidis C, Reynolds M, Hunt M, Lind J, Beckett J, Drummond C, Ghodse H. Substance use in the general hospital. Addictive Behaviors. 2003; 28(2):483-99.

18. Ahmadi J, Benrazavi L. Substance use among Iranian nephrologic patients. American Journal of Nephrology. 2002; 22(3):11-3.

19. Ahmadi J, Benrazavi L. Substance use among Iranian cardiovascular patients. European Journal of Medical Research. 2002; 7(4):89-92.

20. Afshar A, Asadzadeh M, Kargar H, Aghdashi MM, Mirzatolooei F. Opium and opioid abuse in orthopedic inpatients: a cross sectional study in Urmia university of medical sciences. Acta Medica Iranica. 2012; 50(1):66-9.

21. Tabei S, Heydari S, Mehrabani D, Shamsina S, Ahmadi J, Firouzi SM. Current substance use in patients with gastric cancer in Southern Iran. Journal of Cancer Research and Therapeutics. 2006; 2(1):181-2.

22. Ardebili ME, Salehi M, Gharai B, Daneshamuz B, Nassr M, Halebandi MF. A household study on the prevalence of substance misuse in Tehran: the need for other methods to estimate the prevalence. Iranian Journal of Psychiatry. 2006; 1(4):158-61.

23. Smith-Simone S, Maziak W, Ward KD, Eissenberg T. Waterpipe tobacco smoking: knowledge, attitudes, beliefs, and behavior in two US samples. Nicotine \& Tobacco Research. 2008; 10(4):393-8.

24. Afzali S, Saleh A, Rabiei MAS, Taheri K. Frequency of alcohol and substance abuse observed in drivers killed in traffic accidents in Hamadan, Iran. Archives of Iranian Medicine. 2013; 16(1):239-40.

25. Hovens JG, Cantwell DP, Kiriakos R. Psychiatric comorbidity in hospitalized adolescent substance abusers. Journal of the American Academy of Child \& Adolescent Psychiatry. 1994; 33(1): 476-83.

26. Gordon A, Conley J, Gordon J. Physical diseases and addictive disorders: associations and implications. Key Issues in Mental Health. 2015; 179:114-28.

27. Finkelstein NB. Substance abuse treatment: addressing the specific needs of women. Diane Publishing; 2011.

28. McCabe SE. Screening for drug abuse among medical and nonmedical users of prescription drugs in a probability sample of college students. Archives of Pediatrics \& Adolescent Medicine. 2008; 162(2):225-31.

29. Compton WM, Thomas YF, Stinson FS, Grant BF. Prevalence, correlates, disability, and comorbidity of DSM-IV drug abuse and dependence in the United States: results from the national epidemiologic survey on alcohol and related conditions. Archives of General Psychiatry. 2007; 64(1): 566-76.

30. Hasin DS, Stinson FS, Ogburn E, Grant BF. Prevalence, correlates, disability, and comorbidity of DSM-IV alcohol 
abuse and dependence in the United States: results from the national epidemiologic survey on alcohol and related conditions. Archives of General Psychiatry. 2007; 64(1):830-42.

31. Anderson TL. Drug use and gender. Encyclopedia of criminology and deviant behavior. 2001; 4(2):286-9.

32. Obot IS, Room R. Alcohol, gender and drinking problems: perspectives from low and middle income countries. Geneva: World Health Organization. 2005.

33. Degenhardt L, Hall W. The relationship between tobacco use, substance-use disorders and mental health: results from the National Survey of Mental Health and Well-being. Nicotine \& Tobacco Research. 2001; 3(2):225-34.

34. Kendler KS, Prescott CA, Neale MC, Pedersen NL. Temperance board registration for alcohol abuse in a national sample of Swedish male twins, born 1902 to 1949. Archives of General Psychiatry. 1997; 54(1):178-84.

35. Kendler KS, Prescott CA. Cannabis use, abuse, and dependence in a population-based sample of female twins. American Journal of Psychiatry. 1998; 155(2):1016-22.

36. Kendler KS, Neale M, Sullivan P, Corey L, Gardner C, Prescott C. A population-based twin study in women of smoking initiation and nicotine dependence. Psychological Medicine. 1999; 29(1):299-308.
37. Kendler KS, Prescott CA. Cocaine use, abuse and dependence in a population-based sample of female twins. The British Journal of Psychiatry. 1998; 173(4):345-50.

38. Bierut LJ, Dinwiddie SH, Begleiter H, Crowe RR, Hesselbrock V, Nurnberger JI, Porjesz B, Schuckit MA, Reich T. Familial transmission of substance dependence: alcohol, marijuana, cocaine, and habitual smoking: a report from the collaborative study on the genetics of alcoholism. Archives of General Psychiatry. 1998; 55(2):982-8.

39. Haase T, Pratschke J. Risk and protection factors for substance use among young people. 2010.

40. Dick DM, Agrawal A. The genetics of alcohol and other drug dependence. Alcohol Research \& Health. 2008; 31(2):111-2.

41. Ashery RS, Robertson EB, Kumpfer KL. Drug abuse prevention through family interventions. Diane Publishing; 1998.

42. Griswold KS, Aronoff H, Kernan JB, Kahn LS. Adolescent substance use and abuse: recognition and management. American Family Physician. 2008; 77(2):331-6. 